\title{
A direct fed microbial containing a combination of three-strain Bacillus sp. can be used as an alternative to feed antibiotic growth promoters in broiler production
}

\author{
Yueming Dersjant-Li, A. Awati, C. Kromm and C. Evans \\ Danisco Animal Nutrition, Market House, Ailesbury Court, High Street, SN8 1AA Marlborough, Wiltshire, UK
}

\section{Summary}

The objective of the study was to test the effect of a direct fed microbial (DFM) on the performance of broilers compared to an antibiotic growth promoter under large scale, commercial production settings. Three dietary treatments were tested in a completely randomized design including: 1) a control (C) diet containing $500 \mathrm{FTU} / \mathrm{kg}$ phytase and a mixture of xylanase, amylase, protease ; 2) $\mathrm{C}+$ a specific three-strain combination of Bacillus spp. (DFM) and 3) $\mathrm{C}+$ bacitracin methylene disalicylate (BMD). Six, similar commercial broiler houses (15,300 birds per house) were used to give two replicate houses per treatment. The birds (Hubbard x Cobb500) were fed pelleted and crumbled diets ad libitum throughout the 44 day trial period. Due to the large scale, commercial nature of the trial, no significant differences were observed in production parameters among treatments, except that DFM treatment resulted in significantly lower mortality numbers in the last two days (43 to 44d) compared to the control. However, the DFM treatment group showed numerically higher live bodyweight, lower feed conversion ratio (corrected for body weight and mortality) and lower total mortality weight compared to either the control or BMD groups, resulting in an improved production efficiency factor. When compared to control, using DFM resulted in a gross benefit of US $\$ 0.06$ / bird, while using BMD was not cost effective. In conclusion, DFM containing a three-strain combination of Bacillus $s p p$. may be used as an alternative to antibiotic growth promoters, resulting in economic benefit under commercial production settings in broilers fed commercial diets.

Keywords: broilers: Bacillus, enzymes: AGPs: economic benefit

(Received 13 December 2013 - Accepted 6 March 2014)

\section{Introduction}

In today's poultry production systems, disease challenges caused by various pathogens such as E. coli, Salmonella spp., Clostridium perfringens and Campylobacter spp. are of major economic concern (Jayaraman et al., 2013). In some countries, antibiotic growth promoters (AGPs) are used to reduce the impact of these pathogens and control diseases. However, with increasing public concerns regarding bacterial resistance to antibiotics, AGPs have been banned in animal feed in Europe since 2006 and it is expected that in the near future their use will be eliminated from animal feed in other countries. Finding alternatives to AGPs has long been of interest to the feed industry.
Direct-fed microbials (DFMs) are defined as live microorganisms which, when administrated in adequate amounts, confer a health benefit on the host' (FAO/ WHO. 2002). Many studies have shown that DFMs are potential alternatives to AGPs in animal feed (Applegate et al., 2010; Amerah et al., 2013a). DFMs are effective in improving immune response and growth performance of broilers (Lee et al., 2010a,b; Lutful Kabir, 2009).

Substrate supply is essential to maintain the beneficial bacterial population in the gut. Using feed enzymes, such as protease can reduce the indigestible protein which is a substrate for pathogenic bacteria. Carbohydrase can

Corresponding author: Yueming.dersjant-li@dupont.com 
degrade indigestible non-starch polysaccharides (NSPs) and provide substrates for beneficial bacteria (Kiarie et al., 2013). Therefore, the combination of DFMs and multi-enzymes may have a synergic effect and result in better nutrient utilisation and gut health (Momtazan et al., 2011). Previous studies have suggested that the combination of DFMs and enzymes (used in most commercial poultry diets) can be used as growth promoters in broilers (Reddy et al., 2010).

Most of the studies have been carried out under research conditions and only limited studies have been reported under commercial settings. However, for poultry producers, the publication of data from large scale, commercial studies is highly relevant in providing information regarding the expected outcomes of using a DFM in their flocks. Therefore the objective of this study was to determine the performance of broilers fed a DFM product in comparison to AGPs in diets supplemented with multi-enzymes on a commercial farm in the United States.

\section{Materials and methods}

Three dietary treatments were tested in two replicate poultry houses, which were randomly assigned to treatments 1) a control (C) diet containing 500 FTU $/ \mathrm{kg}$ phytase (Phyzyme ${ }^{\circledR}$ XP, Danisco Animal Nutrition/DuPont, Marlborough, Wiltshire, UK, and an enzyme mix containing xylanase, amylase, protease (Axtra ${ }^{\circledR}$ XAP, Danisco Animal Nutrition/DuPont, Marlborough, Wiltshire, $\mathrm{UK})$; 2) C + DFM (containing spores of a three-strain combination of Bacillus sp., Enviva ${ }^{\circledR}$ PRO, Danisco Animal Nutrition/Dupont, Marlborough, Wiltshire, UK); 3) C+ Bacitracin Methylene Disalicylate (BMD) (Zoetis, 100 Campus Drive, Florham Park, NJ 07932, United States).

Diets were formulated to meet commercial recommendations for starter $(0.7 \mathrm{~kg} /$ bird $)$, grower $(1.4 \mathrm{~kg} /$ bird $)$, finisher 1 (1.8 kg/bird) and finisher 2 (until slaughter) and were based on corn and soyabean meal (SBM) and contained 5-12\% distillers dried grains (DDGs). The composition of the control (C) diet is presented in Table 1 . The treatment diets were produced by addition of the test material to the $\mathrm{C}$ diet as a replacement for corn $(0.5 \mathrm{~g} / \mathrm{kg})$. All diets were pelleted $\left(\sim 90^{\circ} \mathrm{C}\right)$ and crumbled after pelleting. Feed and water were supplied ad libitum.

A total of 91,800 day-old mixed-sex broilers (Hubbard $\times$ Cobb 500) were distributed in equal numbers to six
Table 1. Control diet composition and calculated nutritional values

\begin{tabular}{|c|c|c|c|c|}
\hline Diet & Starter & Grower & $\begin{array}{c}\text { Finisher } \\
1\end{array}$ & $\begin{array}{c}\text { Finisher } \\
2\end{array}$ \\
\hline \multicolumn{5}{|l|}{ Ingredients composition, \% } \\
\hline Corn $(7.5 \%)$ & 59.85 & 63.91 & 66.20 & 66.93 \\
\hline Soybean meal (48\% CP) & 26.3 & 20.25 & 16.3 & 14.2 \\
\hline Corn DDGS & 5 & 7.5 & 10 & 12 \\
\hline $\begin{array}{l}\text { Animal protein concentrate } \\
\text { (Pro Plus 57) }\end{array}$ & 6 & 5.75 & 4.3 & 3.35 \\
\hline Animal fat & 0.45 & 0.45 & 1.15 & 1.5 \\
\hline Limestone & 0.8 & 0.8 & 0.85 & 0.9 \\
\hline $\begin{array}{l}\text { Dicalcium phosphate }(18.5 \% \\
\text { P) }\end{array}$ & 0.1 & & & \\
\hline Sodium bicarbonate & 0.13 & 0.055 & & \\
\hline Salt & 0.28 & 0.29 & 0.31 & 0.31 \\
\hline Biolysine & 0.44 & 0.46 & 0.43 & 0.42 \\
\hline Methionine (Alimet) & 0.27 & 0.21 & 0.15 & 0.13 \\
\hline L-Threonine & 0.08 & 0.07 & 0.06 & 0.05 \\
\hline Broiler Vitamins & 0.05 & 0.05 & 0.05 & 0.04 \\
\hline Broiler Trace Mineral & 0.10 & 0.10 & 0.10 & 0.09 \\
\hline Choline Chloride $70 \%$ & 0.06 & 0.05 & 0.04 & 0.03 \\
\hline HYDROXY D3 (HY-D) & 0.03 & & & \\
\hline $\mathrm{XAP}^{1}$ & 0.05 & 0.05 & 0.05 & 0.05 \\
\hline Phytase $^{2}$ & 0.02 & 0.02 & 0.02 & 0.02 \\
\hline \multicolumn{5}{|l|}{$\begin{array}{l}\text { Calculated nutrients } \\
\text { composition }\end{array}$} \\
\hline Protein, \% & 22.17 & 20.06 & 18.10 & 17.09 \\
\hline Fat, \% & 3.30 & 3.59 & 4.45 & 4.94 \\
\hline Fibre, \% & 2.64 & 2.70 & 2.78 & 2.86 \\
\hline Calcium, \% & 0.95 & 0.90 & 0.80 & 0.74 \\
\hline Phosphorus, \% & 0.61 & 0.57 & 0.52 & 0.49 \\
\hline Available Phosphorus, \% & 0.48 & 0.45 & 0.40 & 0.37 \\
\hline Sodium, \% & 0.22 & 0.20 & 0.19 & 0.19 \\
\hline Chloride, \% & 0.26 & 0.26 & 0.27 & 0.27 \\
\hline Methionine, \% & 0.62 & 0.54 & 0.48 & 0.44 \\
\hline Methionine + Cysteine, \% & 1.04 & 0.93 & 0.83 & 0.78 \\
\hline Lysine, \% & 1.35 & 1.20 & 1.06 & 0.98 \\
\hline Available Lysine, \% & 1.20 & 1.06 & 0.93 & 0.86 \\
\hline Choline, mg/kg & 1713 & 1556 & 1442 & 1334 \\
\hline ME Poultry, kcal/kg & 3078 & 3131 & 3199 & 3230 \\
\hline Phytase, FTU/kg & 500 & 500 & 500 & 500 \\
\hline
\end{tabular}

${ }^{1} \mathrm{XAP}$ is a mixed enzyme containing xylanase, amylase and protease (Axtra ${ }^{\circledR}$ XAP, Danisco Animal Nutrition/Dupont); ${ }^{2}$ Phytase is an E. coli phytase enzyme (Phyzyme ${ }^{\circledR}$ XP, Danisco Animal Nutrition/Dupont).

commercial broilers houses (15,300 chicks per house) with a stocking density of $12 \mathrm{birds} / \mathrm{m}^{2}$. The six houses were similar in construction, design, size, compass direction, insulation, heating, ventilation, lighting, watering system, feed equipment and management practices, to minimise residual variation due to housing. Each house had industry standard ventilation and temperature control systems. The birds received vaccination against Marek's, infectious bursal disease, Newcastle disease, infectious bronchitis, laryngotracheitis and coccidiosis (Coccivac B) at the hatchery. The birds were observed daily for clinical signs of disease. Birds were housed on built up litter, as is common commercial practice in the US.

Mortality and culls were recorded daily and calculated weekly. Body weights were measured at $0,7,16,29,38$ 
and $44 \mathrm{~d}$ of the trial; weight gain, feed intake and feed conversion ratio were recorded or calculated for the whole $0-44 \mathrm{~d}$ period. At the end of the grow-out period all birds were slaughtered at the commercial farm via a certified practical processing procedure. The processed number and total live weight of birds were recorded.

Feed conversion ratio (FCR) was calculated as:

$$
\mathrm{FCR}=\frac{\mathrm{kg} \text { feed }}{\mathrm{kg} \text { weight gain }}
$$

Mortality and cull weight adjustment feed conversion ratio (FCRmc) was calculated as

\section{FCRmc}

$$
\begin{aligned}
& =\frac{\mathrm{kg} \text { feed }}{\mathrm{kg} \text { of weight gain }+ \text { weight gain of all mortality and }} \\
& \quad \text { culled birds }
\end{aligned}
$$

Body weight and mortality weight corrected feed conversion ratio (FCRbmc) was calculated by allowing three points reduction in FCRmc for every $100 \mathrm{~g}$ BW increase versus control:

$$
\text { FCRbmc }=\text { FCRmc }-\frac{\text { BWtr }- \text { BWcontr }}{100} * 0.03
$$

Where: BWtr: body weight of bird in treatment group; BWcontr : body weight of bird in control group.

Gross cost/benefit was calculated based on current prices of each feed and live weight at slaughter, assuming no difference in other production cost between the control and test groups. Production efficiency factor (PEF) was used to evaluate the live-bird performance of flocks (Shane, http://www.datapoul.co.uk/wp-content/uploads/ ProductionEfficiencyFactor.pdf). PEF was calculated as:

$$
\mathrm{PEF}=\frac{\text { liveweight }(\mathrm{kg}) * \text { liveability }(\%)}{\text { age at depletion }(\text { days }) * \mathrm{FCR}} * 100
$$

PEF did not take into account the fact that deaths at different ages may have a different level of loss due to mortality (e.g. death early versus late in the production cycle). This discourages the use of PEF in commercial conditions to compare the effect of different additives. Therefore, the authors proposed a modified PEF (MPEF) which corrects for mortality weight and it is calculated as:

$$
\text { MPEF }=\frac{\text { liveweight }(\mathrm{kg}) * \text { liveability }(\%)}{\text { age at depletion }(\text { days }) * \text { FCRmc }} * 100
$$

House means were used to derive mortality, feed intake, body weight gain and feed conversion ratio data. Data were subjected to one way ANOVA using the JMP 10.0 software (SAS Institute Inc, 2012) and treatment means were separated by Tukey HSD test. Differences were considered to be significant at $\mathrm{P}<0.05$.

\section{Results and Discussion}

Due to the large scale production system used and low number of replicates, the only significant difference $(\mathrm{P}<$ $0.05)$ was found in mortality number in the last two days. However, as the trial was carried out at commercial scale with a large number of birds, numerical improvement on production parameters can be considered as relevant.

Weight gains were not significantly affected by dietary treatment, although the DFM diet resulted in numerically higher mean body weights, weight gains and total live bodyweight production when compared to the control and BMD groups (Table 2). Feed conversion ratio was numerically lower in the DFM treatment group compared to the control and BMD groups. The lowest (numerically) calorie conversion ratio (kcal/ $\mathrm{kg}$ BWG) was observed with DFM treatment (Table 2). The weekly and cumulative mortality numbers were presented in Figure 1. Although no significant differences were seen for cumulative mortality numbers among treatments, the DFM diet reduced cumulative mortality by $22 \%$ compared to the control flocks. In the last two days of the trial (43 to $44 \mathrm{~d}$ ), both DFM and BMD groups had lower mortality numbers $(\mathrm{P}<0.05)$ compared to the control (Figure 1). Over the whole trial period, feeding DFM or BMD numerically reduced mortality weight by $40 \%$ and $17 \%$ respectively compared to the birds fed the control diet (Table 2).

This study showed clear advantage of using DFM compared to AGPs in a corn-soy broiler diet containing enzymes and reared in a commercial production system with built up litter. DFM treatment had a positive effect on reducing total mortality number and weight. It is well known that intestinal tracts of newly hatched birds are sterile and contain almost no microflora (Lee et al., 2010a). Microbes from the environment and feed gradually colonise the GI tract and form a stable microflora population over time (Lee et al., 2010a). Dietary DFMs have a positive impact on this process, by helping the birds to develop a beneficial and stable microflora population (Lee et al., 2010a). This may explain the lower mortality rate in the DFM fed birds, especially in the first 
Table 2. Effect of DFM ${ }^{1}$ and $\mathrm{BMD}^{2}$ on growth performance, feed utilisation, mortality and economic benefit in broilers produced under commercial production settings

\begin{tabular}{|c|c|c|c|c|c|}
\hline Treatments & Control & BMD & DFM & SEM & $\mathrm{P}$ \\
\hline \multicolumn{6}{|l|}{ Performance data } \\
\hline No birds start/house & 15300 & 15300 & 15300 & & \\
\hline No birds processed/house & 14901 & 14920 & 14991 & 37.18 & 0.24 \\
\hline Weight processed, kg/house & 39681 & 40012 & 40270 & 222.0 & 0.32 \\
\hline Final weight/bird, kg & 2.66 & 2.68 & 2.69 & 0.02 & 0.56 \\
\hline 0-44 d weight gain/bird, g & 2623.1 & 2641.8 & 2646.4 & 19.82 & 0.68 \\
\hline Feed intake (mort adjusted)/bird, kg & 4.94 & 5.02 & 4.96 & 0.06 & 0.72 \\
\hline Feed conversion ratio(FCR) & 1.894 & 1.905 & 1.871 & 0.03 & 0.75 \\
\hline Mortality weight corrected FCR & 1.875 & 1.89 & 1.861 & 0.03 & 0.81 \\
\hline $\mathrm{FCRbmc}^{3}$ & 1.875 & 1.884 & 1.853 & 0.03 & 0.81 \\
\hline Calorie conversion, kcal/kg BWG & 5962.5 & 6023.1 & 5944.5 & 97.0 & 0.87 \\
\hline Percent Condemned & 0.225 & 0.335 & 0.230 & 0.07 & 0.55 \\
\hline Total mortality number \% & 2.65 & 2.49 & 2.05 & 0.25 & 0.25 \\
\hline Total mortality weight, kg & 846.6 & 700.5 & 503.4 & 110.9 & 0.16 \\
\hline \multicolumn{6}{|l|}{ Economic benefit calculation } \\
\hline Income processed birds, US\$/house ${ }^{4}$ & 71424.9 & 72021.6 & 72486 & & \\
\hline Price feed, US\$/ton ${ }^{5}$ & 433 & 435.5 & 433.86 & & \\
\hline Feed cost, US\$/house & 32534 & 33195 & 32686 & & \\
\hline Gross profit (income-feed cost), US\$ & 38891 & 38827 & 39800 & & \\
\hline Increase above control, US\$ ${ }^{6}$ & & -68 & 917 & & \\
\hline $\mathrm{PEF}^{7}$ & 318.1 & 319.0 & 327.7 & & \\
\hline MPEF 8 & 321.3 & 321.5 & 329.4 & & \\
\hline
\end{tabular}

${ }^{1}$ DFM: a three-strain combination of Bacillus $s p$

2 Bacitracin Methylene Disalicylate (BMD) at inclusion level of $50 \mathrm{ppm}$.

${ }^{3}$ Body weight and mortality weight corrected FCR.

${ }^{4}$ Calculated based on 2013 US market price at US $\$ 1.8 / \mathrm{kg}$ live weight.

${ }^{5}$ Feed cost based on 2013 commercial feed cost for a corn SBM based broiler diet in US market (Janet Remus, personal communication).

6 The gross benefit of DFM was calculated as US $\$ 917 / 15300^{*} 100=6$ US $\$$ cent/bird when compared to control.

${ }^{7}$ PEF: production efficiency factor.

${ }^{8}$ MPEF: modified production efficiency factor.
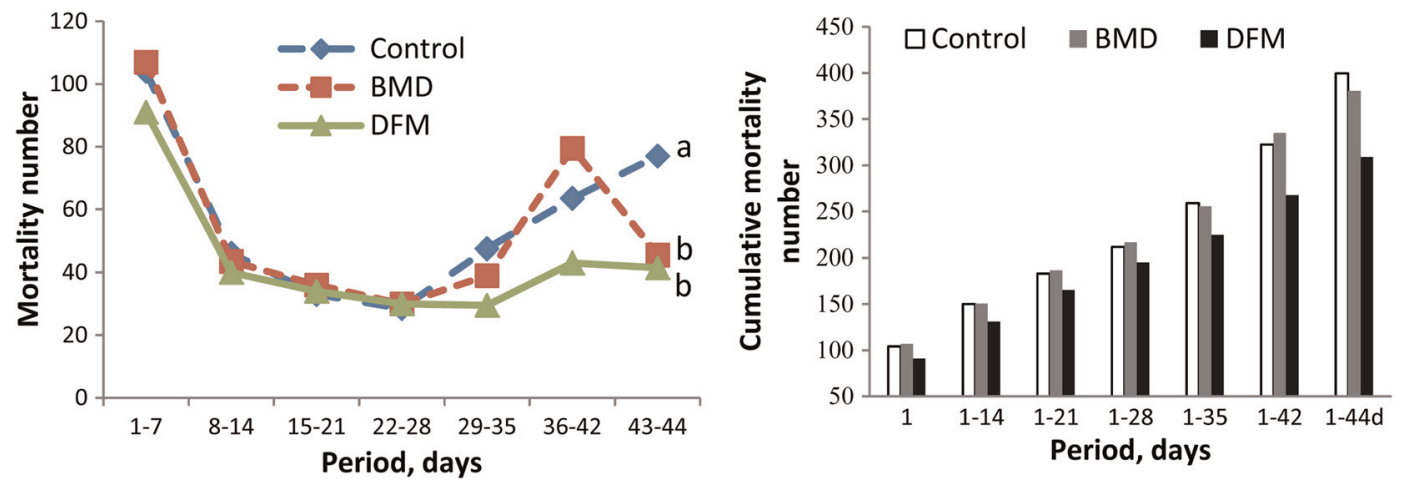

Figure 1. Effect of DFM and BMD on average number of mortality per period (left) and cumulative number per period (right) (15,300 chicks per replicate), significant difference was found in the last two days $(43-44 \mathrm{~d}, P<0.05)$.

week $(12.5 \%$ reduction $v$ s. control) when young birds are more susceptible to pathogens and in pre-slaughter period (36-44 days, $40 \%$ reduction $v$ s. control) where birds are challenged by increased stocking density and the build up of environmental pathogens. The lower mortality in the DFM fed birds suggests improved intestinal health.

When cost benefit was calculated based on income from live weight and feed cost, DFM treatment resulted in 2.3\% higher gross benefit when compared to control (Table 2). This corresponded to the highest Production
Efficiency Factors (PEF \& MPEF) being observed with the DFM treatment (Table 2). The MPEF was estimated as 329.4, 321.3 and 321.5 respectively for DFM, control and BMD treatments.

The DFM used in this study consisted of the spores of a three-strain combination of Bacillus spp., which is suitable for use in animal feed as a live microbial product due to its long shelf life and retained viability during distribution, feed processing and storage (Cartman et al., 2008). Cartman et al. (2008) observed that these spores 
were able to germinate rapidly within the animal, and vegetative cells were detected throughout the GI tract of chickens $20 \mathrm{~h}$ after dosing, when the product was administrated to day- old chicks. Furthermore, it has been found that spore forming probiotics can survive heat treatment (Amerah et al., 2013b) and are compatible with coccidiostats (Kampf et al., 2012).

The numerically improved growth performance and feed utilisation efficiency due to DFM supplementation observed in this commercial scale study is in agreement with previous studies (Lee et al., 2010b; Amerah et al., 2013a; Sen et al., 2012). It has been reported that the use of a DFM containing Bacillus spp. has a positive effect on the performance and immune system of broiler chicks (Teo and Tan, 2007; Kim et al., 2012; Amerah et al., 2013a). Timmerman et al. (2006) observed that chicken specific DFM preparations reduced mortality in broilers.

Timmerman et al. (2006) suggested that the effects of DFMs are inversely related to production index i.e., DFMs are more effective when the production index is low. It was estimated that production index (which ranged between 170 and 310) improved by 1.8 to $31.6 \%$ due to addition of DFMs. In the current study, DFM treatment increased PEF by $3 \%$ and MPEF by $2.5 \%$, which was associated with a high PEF index (327 vs. 318 for the control) observed in this study. MPEF gives a good indication on productivity, as this calculation considers weight gain, survival and mortality corrected feed conversion. However, this calculation does not include feed cost. The gross profit was calculated based on incomes from live weight of birds and feed cost, when compared to the control diet. This calculation demonstrated that using DFM resulted in US\$0.06/ bird gross benefit compared to the control-fed birds, while AGP treatment did not give any economic benefit. This suggests that it may be more cost effective to use DFMs rather than AGPs in broiler production.

Maintaining a stable population of beneficial microflora is important for improving intestinal health and reducing the nutrient and energy cost for gut maintenance. The benefits of using DFM in combination with enzymes have been reported in number of studies (Murugesan, 2013; Romero et al., 2013). In the current study, the basal diet contained phytase, xylanase, amylase and protease, which can reduce the anti-nutritional effect of phytate, increase digestibility of protein and carbohydrates and reduce the endogenous secretions, resulting in increased energy utilisation (Cowieson and Ravindran, 2008). The result being that the activities of the enzymes limit the substrates available for pathogenic bacteria, and can provide substrates for beneficial bacteria (Bedford and Cowieson, 2012). Therefore, enzymes may stimulate the growth of the DFM and result in a synergistic, positive effect on poultry performance. The results from the current study demonstrate that it is beneficial to use DFM in broiler diet supplemented with multi-enzymes under commercial settings.

\section{Conclusions}

Supplementation of a three-strain combination of Bacillus $s p p$. to broilers diets reduced mortality and improved production efficiency. The results from this study indicated that DFM may be used as alternative to AGP and can result in economic benefits under commercial production settings with broilers fed commercial diets containing multi-enzymes.

\section{Acknowledgments}

The authors would like to thank Du Pont/Danisco Animal Nutrition, UK Ltd for their financial support of this research.

\section{Declaration of Interest}

Yueming Derjant-Li, Ajay Awati and Ceinwen Evans are employees of Du Pont/Danisco Animal Nutrition, UK Ltd.

\section{References}

Amerah A.M., Jansen van Rensburg C., Plumstead P.W., Kromm C. and Dunham S. (2013a) Effect of feeding diets containing a probiotic or antibiotic on broiler performance, intestinal mucosa-associated avian pathogenic E. coli and litter water-soluble phosphorus. Journal of Applied Animal Nutrition, Vol. 1; e7; page 1 of 7. doi:10.1017/ jan.2013.4.

Amerah A.M., Quiles A., Medel P., Sánchez J., Lehtinen M.J. and Gracia M.I. (2013b) Effect of pelleting temperature and probiotic supplementation on growth performance and immune function of broilers fed maize/soy-based diets. Animal Feed Science and Technology, 180: $55-63$.

Applegate T.J., Klose V., Steiner T., Ganner A. and Schatzmayr G. (2010) Probiotics and phytogenics for poultry: Myth or reality? Journal of Applied Poultry Research, 19:194-210.

Bedford M.R. and Cowieson A.J. (2012) Exogenous enzymes and their effects on intestinal microbiology. Animal Feed Science and Technology, 173: $76-85$.

Cartman S.T., La Ragione R.M. and Woodward M.J. (2008) Bacillus subtilis Spores Germinate in the Chicken Gastrointestinal Tract. Applied and Environmental Microbiology, 74: 5254-5258.

Cowieson A.J. and Ravindran V. (2008) Effects of exogenous enzymes in maize-based diets varying in nutrient density for young broilers: growth performance and digestibility of energy, minerals and amino acids. British Poultry Science, 49: 47-44. 
Jayaraman S., Thangavel G., Kurian H., Mani R., Mukkalil R. and Chirakkal H. (2013) Bacillus subtilis PB6 improves intestinal health of broiler chickens challenged with Clostridium perfringens-induced necrotic enteritis. Poultry Science, 92:370-374.

Kiarie E., Romero L.F. and Nyachoti C.M. (2013) The role of added feed enzymes in promoting gut health in swine and poultry. Nutrition Research Reviews 26: 71-88.

FAO/WHO. (2002) Guidelines for the evaluation of probiotics in food. Report of a joint Food and Agriculture Organisation (FAO)/World Health Organisation (WHO) working group on drafting guidelines for the evaluation of probiotics in food. World Health Organisation. http:// www.who.int/foodsafety/fs_management/en/probiotic_guidelines.pdf.

Kampf D., Rovers M. and Nakamura N. (2012) Spore forming probiotic Bacillus subtilis C-3102 in pig and poultry diets. http://www. orffa.com/site/products-probiotics-calsporin-uk/\$FILE/Kampf-ea2012-ATA-abstract-Spore-forming-probiotic-Bacillus-subtilis-C3102in-pigs-and-poultry.pdf.

Kim J.S., Ingale S.L., Kim Y.W., Kim K.H., Sen S., Ryu M.H., Lohakare J.D., Kwon I.K. and Chae B.J. (2012) Effect of supplementation of multi-microbe probiotic product on growth performance, apparent digestibility, cecal microbiota and small intestinal morphology of broilers. Journal of Animal Physiology and Animal Nutrition (Berl), 96: 618-626.

Lee K.W., Lillehoj H.S. and Siragusa G.R. (2010a) Review: direct-fed microbials and their impact on the intestinal microflora and immune system of chickens. The Journal of Poultry Science 47: 106-114.

Lee K.W., Lee S.H., Lillehoj H.S., Li G.X., Jang S.I., Babu U.S., Park M.S., Kim D.K., Lillehoj E.P., Neumann A.P., Rehberger T.G. and Siragusa G.R. (2010b) Effects of direct-fed microbials on growth performance, gut morphometry, and immune characteristics in broiler chickens. Poultry Science 89: 203-216.

Lutful Kabir S.M. (2009) The role of probiotics in the poultry industry. International Journal of Molecular Sciences, 10: 3531-3546.
Momtazan R., Moravej H., Zaghari M. and Taheri H.R. (2011) A note on the effects of a combination of an enzyme complex and probiotic in the diet on performance of broiler chickens. Irish Journal of Agricultural and Food Research, 50: 249-254.

Murugesan G.R. (2013) Characterisation of the effects of intestinal physiology modified by exogenous enzymes and direct-fed microbial on intestinal integrity, energy metabolism, body composition and performance of laying hens and broiler chickens. Ph. D. Thesis, Iowa State University.

Reddy P.V.M., Kondal R.K., Kuhad R.C., Shashi K.M. and Gnana P.M. (2010) Effect of supplementation of enzymes and probiotics on performance of broiler chicken. Indian Journal of Poultry Science, 45: 361-363.

Romero L.F., Indrakumar S.E. and Ravindran V. (2013) Influence of combinations of a direct-fed microbial and exogenous enzymes on the nutrient digestibility in broilers at $11 \mathrm{~d}$ and $21 \mathrm{~d}$ of age. Poultry Science 92(E-Suppl. 1):88.

Sen S., Ingale S.L., Kim Y.W., Kim J. S., Kim K. H., Lohakarea J. D., Kim E. K., Kim H. S., Ryu M. H., Kwon I. K. and Chae B.J. (2012) Effect of supplementation of Bacillus subtilis LS 1-2 to broiler diets on growth performance, nutrient retention, caecal microbiology and small intestinal morphology. Research in Veterinary Science 93: $264-268$

Shane S. What's your 'PEF'? Live Production Management. http://www. datapoul.co.uk/wp-content/uploads/ProductionEfficiencyFactor.pdf

Teo A.Y. and Tan H.M. (2007) Evaluation of the Performance and Intestinal Gut Microflora of Broilers Fed on Corn-Soy Diets Supplemented With Bacillus subtilis PB6 (CloSTAT). Journal of Applied Poultry Research, 16: 296-303.

Timmerman H.M., Veldman A., van den Elsen E., Rombouts F.M. and Beynen A.C. (2006) Mortality and growth performance of broilers given drinking water supplemented with chicken-specific probiotics. Poultry Science 85:1383-1388. 